\title{
TRABAJADORES AGRÍCOLAS Y CONFLICTIVIDAD LABORAL EN LA ANDALUCÍA DEL SIGLO XVIII ${ }^{1}$
}

\author{
Jesús Manuel GonZález Beltrán \\ UNIVERSIDAD DE CÁDIZ
}

\section{RESUMEN}

En esta investigación nos centramos en dos aspectos, por un lado, las condiciones laborales de los trabajadores del campo en los siglos modernos. Y, por otro, los conflictos que por incumplimiento o modificaciones de esas condiciones se producen entre los trabajadores agrícolas y sus empleadores.

Palabras claves: trabajadores agrícolas, condiciones laborales, Andalucía, siglo XVIII.

\section{ABSTRACT}

We will work two points of views through our research, firstly work conditions of wageearning worker during early Modern Age, and secondly the conflict between the landlords and the agricultural workers due to faults or modifications of those conditions.

Key words: agricultural workers, labour's conditions, Andalucía (Spain), XVIII century.

\section{TRABAJADORES Y CONFLICTO EN EL MUNDO RURAL}

Los estudios sobre el mundo rural en la Edad Moderna presentan, en general, una laguna bastante incomprensible, ya que no se ocupan, o lo hacen de forma soslayada, de uno de sus sujetos sociales más significativos, tanto por el alto número de sus efectivos como por su esencial incidencia en el desarrollo de la actividad agraria. Nos estamos refiriendo a los trabajadores del campo ${ }^{2}$.

\footnotetext{
Este estudio se desarrolla en el marco del grupo de investigación HUM-614, "Grupos de poder en la Baja Andalucía Moderna", financiado por el Plan Andaluz de Investigación.

2 En los últimos años han visto la luz algunos trabajos que son la excepción a este panorama historiográfico desolador. Así, para el periodo inicial de la Edad Moderna contamos con el libro de BORRERO FERNÁNDEZ, M.: La organización del trabajo. De la explotación de la tierra a las relaciones laborales en el campo andaluz (siglos XIII-XVI), Sevilla, 2003; y para el siglo XVIII con los estudios de FLORENCIO PUNTAS, A. y LÓPEZ MARTÍNEZ, A.L.: "El trabajo asalariado en la agricultura de la Baja Andalucía. Siglos XVIII y XIX", Historia
} 
Con frecuencia, se excusa la escasez de estudios sobre este grupo sociolaboral aludiendo a la falta de fuentes documentales en las que se puedan detectar, de forma directa, las opiniones, las pretensiones o las preocupaciones de los propios trabajadores. Esta claro, que se trata de unos individuos con nula formación académica, mínimos recursos económicos y, por supuesto, ausentes de los órganos locales de gobierno, todo lo cual repercute en una incapacidad para poderse manifestar a través de los cauces ordinarios establecidos. Ahora bien, siempre queda el recurso a otras fuentes de información que, aunque de forma indirecta, nos pueden ilustrar sobre los trabajadores agrícolas y su problemática. Nos referimos, por ejemplo, a las actas capitulares y ordenanzas municipales, que recogen la respuesta dada por las autoridades locales ante determinadas situaciones o demandas planteadas por los operarios del campo ${ }^{3}$. Del mismo modo, el profesor Fontana, aludiendo al campesinado en general, señala que la evolución social de éste "ha de reconstruirse en

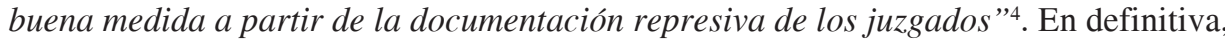
voces secundarias para poder captar los susurros velados de los trabajadores.

A la carencia de fuentes se añade un problema de método y conceptualización. La idea predominante mantiene que el obrero asalariado, como estereotipo proletario con unas concretas peculiaridades, sólo se entiende en el contexto del marco socioeconómico del capitalismo contemporáneo, es decir siglos XIX y XX. Con esta premisa, la existencia de trabajadores en el mundo rural de la Edad Moderna queda invalidada o, cuanto menos, difuminada. Primero, porque se pone en duda el carácter capitalista del latifundio agrícola como forma de explotación ${ }^{5}$. Y segundo, porque se niega la caracterización de los operarios del campo del periodo moderno como proletarios o, si no se quiere utilizar este concepto por sus connotaciones sociopolíticas contemporáneas, como trabajador asalariado puro $^{6}$. Sobre ello debemos apuntar que las generalizaciones siempre ocultan parte de la realidad. Para el caso concreto de la zona estudiada, la campiña gaditana, en la Baja Andalucía, son palpables en plena Edad Moderna las relaciones de producción capitalista en la actividad agrícola, con unas explotaciones claramente orientadas a la producción de excedentes (trigo, vino, aceite) para su comercialización y con el uso intensivo de asalaria-

Agraria, 21 (2000), pp. 99-126 y "El mercado de trabajo en la Andalucía latifundista del Antiguo Régimen: ¿intervención o contratación?", Historia Agraria, 30 (2003), pp. 63-85. Para otros ámbitos territoriales no andaluces, consultar las aportaciones de PEIRÓ ARROYO, A.: Jornaleros y mancebos. Identidad, organización y conflicto en los trabajadores del Antiguo Régimen, Barcelona, 2002, MELÓN JIMÉNEZ, M.A.: "El mundo del trabajo. Jornaleros en la extremadura del siglo XVIII", en CASTILLO, S. y FERNÁNDEZ, R. (Coords.): Campesinos, artesanos, trabajadores, Leida, 2001, pp. 77-92 y ROCA FABREGAT, P.: “¿Quién trabajaba en las masías? Criados y criadas en la agricultura catalana (1670-1870)”, Historia Agraria, 35 (2005), pp. 49-92.

3 Sobre la utilización de estas fuentes CORTÉS PEÑA, A.L.: "Tensiones campesinas en la Andalucía Moderna: una aproximación”, en GONZÁLEZ DE MOLINA, M. (Ed.): La historia de Andalucía a debate. 1. Campesinos y jornaleros, Granada, 2000, p. 45.

4 FONTANA, J.: "Los campesinos en la Historia: reflexiones sobre un concepto y unos perjuicios", Historia Social, 28 (1997), p. 8.

5 Sobre esta cuestión pueden verse los diversos trabajos incluidos en SEVILLA-GUZMÁN y GONZÁLEZ DE MOLINA (Eds.): Ecología, campesinado e historia, Madrid, 1993. Y, GONZÁLEZ DE MOLINA y SEVILLAGUZMÁN: "Perspectivas socioambientales de la historia del movimiento campesino andaluz", en GONZÁLEZ DE MOLINA, M. (Ed.): La historia de Andalucía..., pp. 239-286.

6 Autores como GARRABOU, R.: "Salarios y proletarización en la agricultura catalana de mediados del siglo XIX", Hacienda Pública Española, 8-9 (1987), p. 355, indican que los trabajadores agrícolas sólo perciben en salarios una pequeña parte de lo que necesitan para mantenerse. Por otra parte, SEVILLA-GUZMÁN, E.: La evolución del campesinado en España, Barcelona, 1979, p. 35, señala como muchos proletarios no son sino campesinos con pequeñas explotaciones insuficientes para su subsistencia. 
$\operatorname{dos}^{7}$ que, en su gran mayoría, no tienen propiedad alguna y dependen, de forma exclusiva, de la remuneración que obtengan por su trabajo, en metálico o en especie, para poder subsistir.

Se constata, por tanto, la presencia de personal asalariado en el agro andaluz durante la Edad Moderna, los cuales reciben, en la documentación consultada, una variada denominación: peones, gañanes, trabajadores del campo, cavadores, braceros y jornaleros. Destacar como las autoridades locales suelen referirse a este grupo como trabajadores, sin más, o trabajadores del campo, mientras que los documentos oficiales que tienen su origen en organismos o cargos de la administración estatal suelen emplear la denominación de jornalero, que será la que, a pesar de su origen genérico, "el que trabaja por su jornal" en cualquier tipo de trabajo, terminará por imponerse en el siglo XIX para aludir a los obreros agrícolas.

La exigua atención prestada por la historiografía a los trabajadores del campo en los siglos modernos, así como las teorías mencionadas que cuestionan o matizan su propia existencia, tienen como consecuencia directa el que este colectivo no se vea incluido, salvo raras excepciones, en líneas de investigación tales como las dedicadas a la conflictividad social ${ }^{9} \mathrm{o}$ a las manifestaciones de protesta labora $l^{10}$. La carencia de estudios sobre estos aspectos no hace sino consolidar la falsa idea de que el mundo rural, en lo que a sus trabajadores y a las relaciones laborales se refiere, era una balsa de aceite, un escenario de paz y concordia. Por otra parte, la escasez de hechos violentos destacables documentados o las limitadas repercusiones de los que tuvieron lugar han permitido corroborar este panorama de placidez. Esta cuestión, no obstante, conviene que sea puntualizada.

Así, el palpable conformismo que los trabajadores agrícolas de la Edad Moderna parecen mostrar no tiene porque ser manifestación de una postura voluntaria. Es decir, pue-

7 Postura defendida desde hace bastantes años por BERNAL, A.M.: Economía e historia de los latifundios, Madrid, 1988. Interesa sobre este aspecto la llamada de atención de CARO CANCELA, D.: "La reforma agraria liberal y los campesinos en Andalucía”, en GONZÁLEZ de MOLINA, M. (Ed.): La historia de Andalucía..., pp. 57-78, en concreto p. 61, al señalar como las herramientas teóricas utilizadas por Sevilla-Guzmán y el Seminario de Historia agraria de la U. de Granada pueden ser válidas "en gran parte de las poblaciones rurales altoandaluzas, pero muestran claramente ser insuficientes para comprender el contexto histórico de las llamadas "agrociudades" de la Baja Andalucía en el paso del Antiguo al Nuevo Régimen”.

8 Dicha definición, recogida en COVARRUBIAS, Sebastián: Tesoro de la Lengua Castellana o Española, Madrid, 1610, edición facsímil, Madrid, 1977, p. 717, se repite, sin apenas modificación, en el Diccionario de Autoridades, Madrid, 1726, tomo II, p. 321 y en el actual Diccionario de la Lengua Española, Madrid, 1992, p. 852 .

9 No encontramos nada sobre los trabajadores agrícolas en la recopilación realizada por MARTÍNEZ RUÍZ, E. y ROMERO SAMPER, M.: "Conflictos y conflictividad social en la España del siglo XVIII”, en Coloquio Internacional Carlos III y su siglo, tomo I, Madrid, 1990, pp. 387-423; o en el monográfico dedicado a la "Conflictividad y represión en la sociedad moderna" que incluye el número 22 de Estudis. Revista de Historia Moderna; ni en las aportaciones que contiene el reciente libro de FORTEA, J.I., GELABERT, J.E. y MANTECÓN, T.A. (Eds.): Furor et rabies. Violencia, conflicto y marginación en la Edad Moderna, Santander, 2002. Incluso los trabajadores no aparecen en el artículo de SAAVEDRA, Pegerto: "La conflictividad rural en la España Moderna", Noticiario de Historia Agraria, 12 (1996), pp. 21-47, que resume las comunicaciones presentadas al VII coloquio del Seminario de Historia Agraria.

10 Nada sobre conflictos laborales de los operarios del campo de la Edad Moderna en CASTILLO, S. (Coord.): El trabajo a través de la historia, Madrid, 1996, ni en CASTILLO, S. y ORTÍZ DE ORDUÑO, J.M. (Coords.): Estado, protesta y movimientos sociales. Actas del III Congreso de Historia Social de España, Bilbao, 1998. En este último, se localizan dos artículos, uno de DOMÍNGUEZ ORTÍZ, A.: "La conflictividad laboral en el Antiguo Régimen español", pp. 495-516, y otro de NIETO SÁNCHEZ, J.A.: "La conflictividad laboral en España durante el siglo XVIII", pp. 551-567, ambos dedicados a los conflictos laborales en el ámbito de la industria. 
de ser fruto de la imposición o de la presión de los distintos poderes que rigen la sociedad en el Antiguo Régimen. La predicación religiosa que, al establecer el origen de los males en los propios pecados de los que los padecen, incita a la resignación, o los mecanismos coercitivos que ponen en práctica las autoridades para disuadir cualquier acción de protesta, son aspectos que favorecen las actitudes de pasividad ${ }^{11}$.

Por otro lado, hay una tendencia a relacionar conflicto con violencia, de tal modo que sólo se admite la conflictividad si ésta se evidencia externamente de una forma violenta ${ }^{12}$. Frente a esta línea de la historiografía que sólo hace hincapié en las revueltas y motines visibles, surge una nueva corriente de investigación que señala la importancia de las "formas cotidianas de resistencia", es decir, aquellos actos que, con poca o ninguna organización y evitando la confrontación directa, intentan "mitigar o negarse a peticiones impuestas por clases superiores o avanzar en sus propias peticiones frente a estas clases superiores" $"$. Esta conflictividad latente es difícil de detectar por la propia naturaleza de sus formas de manifestación, generalmente anónimas y disimuladas, por lo que se propone recurrir para intentar atisbarla a las fuentes judiciales, aquellas que recogen los comportamientos anómalos, contrarios a las normas de convivencia establecidas. No obstante, esta metodología debe ponerse en práctica con mucha precaución, ya que podemos caer en errores graves, tales como confundir las simples actitudes individuales de delincuencia con toda una protesta social colectiva, o el reducir esta última a una visión exclusivamente criminalista.

Por último, el pretendido conformismo de los trabajadores del campo puede derivar del propio proceso metodológico de selección y jerarquía al que se someten los factores que intervienen en los orígenes de cualquier conflicto. Salvo casos muy concretos, las revueltas, los motines, se desencadenan por la concurrencia de varios factores interrelacionados entre sí, de los cuales se suele destacar a alguno de ellos, que sería el predominante, mientras que los restantes tendrían un papel subalterno. Así, por ejemplo, se incide, continuamente, en el motín de subsistencia, pero no se recalca que los protagonistas del mismo son, en numerosas ocasiones, asalariados agrícolas en periodo de paro forzoso lo que les impide ganar un jornal con el que adquirir su sustento. En este caso, la posible protesta de los jornaleros por la falta de trabajo queda disimulada por el problema del hambre.

La realidad de los trabajadores del campo y de sus relaciones laborales en la Edad Moderna, como nos proponemos demostrar en este artículo, dista mucho de esa visión arraigada de tranquilidad y armonía. El conflicto, tanto en su versión soterrada como en su manifestación abierta y abrupta, es una constante en el mundo laboral agrario. En esta investigación, utilizando preferentemente la documentación generada por las instituciones de

11 Sobre esta cuestión ANDRÉS-GALLEGO, J.: "La protesta social en la Andalucía del siglo XVIII", en El movimiento obrero en la historia de Cádiz, Cádiz, 1988, p. 17. Con interesantes aportaciones los artículos de SCHILLING, H.: "El disciplinamiento social en la Edad Moderna: propuestas de indagación interdisciplinar y comparativa" y DINGES, M.: "El uso de la justicia como forma de control social en la Edad Moderna", ambos en FORTEA, J.I., GELABERT, J.E. y MANTECÓN, T.A. (Eds.): Op. Cit., pp. 17-45 y 47-68.

12 Una crítica a esta postura en ARÓSTEGUI, J.: "Violencia, sociedad y política: la definición de la violencia", Ayer, 13 (1994), p. 30.

13 Un resumen de esta teoría en SCOTT, J.: "Formas cotidianas de rebelión campesina", en Historia Social, 28 (1997), pp. 13-39. La versión original en The Journal of Peasant Studies, 13 (1986). En la misma línea THOMPSON, E.P.: Miseria de la Teoría, Barcelona, 1981. 
gobierno local (actas capitulares, bandos y edictos, expedientes de orden público, legislación y reglamentos laborales, etc.), pretendemos aproximarnos, desvelar, toda una serie de aspectos relevantes de la conflictividad laboral en la actividad agraria. Así, y en el siguiente orden, plantearemos cuáles son las premisas fundamentales del marco laboral de los asalariados del campo, incidiendo en aquellos factores que repercuten, moldean o alteran su constitución. Especialmente, el tejido legal, que discurre entre la costumbre y la imposición, y la trama socioeconómica, entendida como el conjunto de relaciones que se dan entre los distintos colectivos involucrados, directa o indirectamente, en el desarrollo de la actividad agrícola. Del mismo modo, reflejaremos los factores que repercuten en la contratación de los operarios y en las condiciones de dichos contratos: el número de trabajadores, las necesidades y ritmos de las tareas agrícolas y los cambios de mentalidad empresarial.

A continuación, centraremos nuestro interés en las manifestaciones de la protesta laboral de los operarios del campo. Con respecto al conflicto laboral, interesa conocer las causas que lo motivan, las formas a través de las cuales se hace patente la queja o la reivindicación, la amplitud y la incidencia de las acciones o medidas puestas en prácti$\mathrm{ca}, \mathrm{y}$, finalmente, observar las repercusiones positivas y negativas que se derivan de todo ello. Este último aspecto entroncaría directamente con las conclusiones, que irían en la línea de valorar la posible efectividad de las manifestaciones de protesta, de las acciones de reivindicación, llevadas a cabo por los trabajadores con el objetivo de conseguir un marco laboral más favorable a sus intereses o, al menos, no tan perjudicial para los mismos.

El espacio temporal elegido corresponde al siglo XVIII, un periodo que se caracteriza por un incremento significativo de los efectivos humanos, lo que tiene repercusiones no sólo sobre la mano de obra disponible sino también sobre la roturación de tierras, la demanda de recursos alimenticios o el precio de éstos. Por otro lado, asistimos a la aparición de toda una serie de nuevos planteamientos (políticos, sociales, económicos) que, al poner en entredicho algunos de los pilares básicos de la estructura social imperante, van a potenciar el que surjan y se desarrollen fricciones y controversias hasta entonces inexistentes o dormidas ${ }^{14}$. Así, en el mundo agrario, se empieza a cuestionar el señorío y las vinculaciones, las tierras públicas, las reglamentaciones anquilosadas y las prácticas tradicionales, es decir, todo aquello que impide un desarrollo "moderno y libre" de las explotaciones agrícolas. Difícilmente encontraremos a los trabajadores del campo entre los precursores de estas iniciativas reformistas o de ruptura, pero, de lo que no cabe duda, es que se verán involucrados en ellas y que deberán adaptar sus estrategias de supervivencia para no quedar convertidos en meras piezas manejadas por otras manos.

Planteábamos en el título un espacio geográfico amplio: Andalucía. Ahora bien, los estudios realizados, la mayoría de ellos referidos a la Edad Contemporánea, señalan que el colectivo de los trabajadores agrícolas andaluces, bajo una caracterización general, presenta peculiaridades concretas dependiendo de la zona de Andalucía que analicemos. Para evitar cualquier tipo de controversia en este sentido, debemos indicar que nuestra inves-

14 En esta línea BERNAL, A.M.: "Sobre campesinos y jornaleros de la historiografía tradicional a recientes investigaciones”, en GONZÁLEZ DE MOLINA, M. (Ed.): La historia de Andalucía..., p. 217, indica lo determinante que resulta "la etapa de 1760-1845 en la configuración de la estructura social y económica del campo andaluz como base de las tensiones a partir de entonces generadas". 
tigación se basa en documentación que proviene de los archivos de localidades de la campiña jerezana (Jerez de la Frontera, El Puerto de Santa María, Sanlucar de Barrameda, Medina Sidonia, etc.), que se ha complementado con referencias bibliográficas que versan sobre los asalariados del campo en localidades de la Andalucía Occidental (Cádiz, Sevilla, Córdoba). Es éste, por tanto, el marco geográfico del presente artículo. Una zona, en el siglo XVIII, que presenta una estructura socioeconómica bastante homogénea, con predominio de la actividad agrícola, en la que destaca la gran explotación, generalmente gestionada por arrendatarios, dedicada al cereal, que precisa de una mano de obra muy abundante. Con un viñedo en expansión en el que, junto al pequeño viticultor, conviven nuevos cosecheros que tienen como objetivo no sólo la producción de uva sino también la comercialización de los vinos en el mercado exterior, los cuales están introduciendo nuevas fórmulas de gestión en sus empresas. Igualmente, la cercanía de la urbe gaditana, con más de 50.000 habitantes y un puerto próspero abierto al comercio americano y europeo genera muy buenas expectativas para la venta de la producción agraria ${ }^{15}$.

Veamos, pues, las condiciones laborales y las manifestaciones de protesta de los trabajadores agrícolas de la baja Andalucía en el siglo XVIII.

\section{LOS TRABAJADORES DEL CAMPO: CONDICIONES LABORALES}

El trabajo en las explotaciones agrícolas durante la Edad Moderna no estaba sometido, como puede ocurrir hoy en día, a una estricta regulación estatal que fijara las obligaciones y los derechos tanto de los asalariados como de los empresarios empleadores. No existía, al menos para la Corona de Castilla, un marco legal de obligado cumplimiento en todo su territorio que estableciera cuáles debían ser las pautas que rigieran las relaciones laborales en el ámbito agrario. Y afirmamos que no había una normativa general, porque difícilmente podemos considerar como tal a las cuatro leyes básicas, de origen medieval, que se reiteran en las distintas recopilaciones legales de la Edad Moderna ${ }^{16}$. Estas normas, que datan del reinado de Enrique II, concretamente de los años 1369-1373, nos descubren la inquietud de determinados sectores socioeconómicos influyentes ante la escasez de mano obra originada por los efectos letales de las epidemias de mediados del siglo XIV. Así, la primera obliga a los jornaleros a presentarse en la plaza del pueblo para su contratación "cada día en quebrando el alba", y establece una jornada laboral de sol a sol, al indicar que los trabajadores "salgan del lugar saliendo el sol, para hacer las labores en que fueron alquilados, y labren todo el día en tal manera que salgan de las dichas labores en tiempo que lleguen a la villa o lugar donde fueron alquilados en poniéndose el sol". La segunda, tras señalar que se debe pagar al obrero al finalizar su jornada, siempre que éste así lo quiera, limita a 12 el número de jornaleros que cada patrón puede emplear dia-

15 Sobre estos aspectos SÁNCHEZ GONZÁLEZ, R.: El comercio agrícola de la Baja Andalucía con América en el siglo XVIII, El Puerto de Santa María, 2000; MALDONADO, J.: La formación del capitalismo en el marco del Jerez, Madrid, 1999; y GONZÁLEZ BELTRÁN, J.M.: "Aproximación social a la estructura del capital. Jerez de la Frontera 1750-1790”, Trocadero. Revista de Historia Moderna y Contemporánea, 12-13 (2000-2001), pp. 211 252.

16 Nos referimos a las Ordenanzas Reales de Alonso Díaz de Montalvo en tiempos de los Reyes Católicos, la Nueva Recopilación en el reinado de Felipe II y la Novísima Recopilación, Madrid, 1804, encontrándose en esta última en el libro VIII, título XXVI. 
riamente, a fin de que tengan "comunalmente todos obreros para sus labores". Mientras que la tercera, con el objetivo declarado de evitar los excesos practicados por los jornaleros, ordena que se establezca tasa en los salarios, "según que los precios de las viandas valieren”, facultando para ello al concejo junto con "los hombres buenos”, bajo la supervisión de los alcaldes. La cuarta y última prohibe la presencia de mujeres, salvo las "viejas y flacas”, en las cuadrillas de trabajadores. Salvo ésta, en la que priman los motivos morales ${ }^{17}$, las otras tres leyes inciden en unos definidos intereses económicos, los de los grupos empleadores: contar con trabajadores suficientes, sometidos a extensas jornadas de trabajo y con unos salarios tasados a la baja.

Los objetivos nombrados no eran nuevos, los podemos detectar, acompañados de algunas otras directrices, en numerosos ordenamientos, fueros y ordenanzas municipales al menos desde el siglo $\mathrm{XI}^{18}$. Y es más, a falta de una completa normativa estatal, serán los gobiernos locales, también durante la última etapa del medievo y la Edad Moderna, los que se encarguen de regular la actividad laboral que se desarrolle en su ámbito de actuación. En estas reglamentaciones, que reiteramos son elaboradas e impuestas por la parte empleadora ${ }^{19}$, se suele incidir en las siguientes cuestiones: salario, duración de la jornada laboral, obligación de trabajar, cumplimiento de los contratos, calidad o intensidad del trabajo realizado y, en algunos casos, la defensa de los trabajadores locales frente a los foráneos ${ }^{20}$. Veamos algunos de los aspectos más interesantes, aquellos que, como en el próximo apartado comprobaremos, ocasionan mayores quejas y demandas de los trabajadores.

Comenzaremos con el salario, sobre el cual hay que indicar que no se daba nada parecido a un salario base o salario tipo de aplicación general para el trabajo agrario. La

17 RUSSO, Saverio: "Los asalariados en la cerealicultura de la Italia meridional, siglos XVIII-XIX", Historia Agraria, 25 (2001), p. 70, indica que son los códigos culturales predominantes los que desalientan el trabajo femenino. Y recoge un comentario en tal sentido: "Un hombre que permite a su mujer trabajar fuera del hogar pone en peligro su honor de dos modos: directamente, poniendo de manifiesto que no es capaz de mantener a su familia por sí mismo (...) e indirectamente, porque tendrá menos capacidad de control sobre la actividad sexual de ella”. En la Andalucía del siglo XVIII las mujeres no se cuentan entre los efectivos contratados para las labores del campo, así lo atestiguan el ilustrado Olavide: "ir a trabajar al campo es cosa de que no hay ejemplo; ha muchos siglos que no se ve que una mujer, ni un muchacho, ayude a los trabajos rústicos”, en su informe sobre la ley agraria (cita tomada de MERCHÁN, A.: La reforma agraria en Andalucía, Sevilla, 1996, p. 166) o el prior de la Cartuja de Jerez, que, de forma muy peyorativa, dice que las mujeres de los jornaleros "viven en una perpetua y vituperable ociosidad y la más aplicada con cuidar a su marido e hijos y hacer alguna colada o calceta ha dado todo cuanto puede a su casa, familia y al Estado”, A.H.N., Sección Estado, leg. 3.165, año 1786. Una defensa del trabajo femenino, criticando el que no sea computado en los censos y catastros, puede verse en SARASÚA, Carmen: "El análisis histórico del trabajo agrario: cuestiones recientes", Historia Agraria, 22 (2000), pp. 86-87.

18 Sobre la normativa laboral medieval son interesante las aportaciones de VASALLO, Rosana: "Estudio comparativo de los jornaleros en la Extremadura castellano-leonesa y Andalucía. Siglos XIII-XVI", en El trabajo en la Historia, Salamanca, 1996, pp. 19-38; BORRERO FERNÁNDEZ, M.: La organización del trabajo..., pp. 209-216; y sobre todo, FLORENCIO PUNTAS, A. y LÓPEZ MARTÍNEZ, A.L.: "El mercado de trabajo...", pp. 65-69.

19 No olvidemos las estrechas relaciones existentes entre los grandes propietarios y labradores con las élites de gobierno local, siendo, en muchas ocasiones, unas mismas personas. Sobre el papel de los gobiernos locales en la regulación interesada y partidista de la actividad agraria GONZÁLEZ DE MOLINA, M.: "La funcionalidad de los poderes locales en una economía orgánica", Noticiario de Historia Agraria, 6 (1993), pp. 9-23 y GRUPO DE ESTUDIOS AGRARIOS: "Transformaciones agrarias y cambios en la funcionalidad de los poderes locales en la Alta Andalucía, 1750-1950", Noticiario de Historia Agraria, 10 (1996), pp. 35-66.

20 SARASÚA, Carmen: Art. Cit., p. 90 y FLORENCIO PUNTAS, A. y LÓPEZ MARTÍNEZ, A.L.: "El mercado de trabajo...", pp. 65-76. 
casuística es profusa y compleja al intervenir variados factores tanto en la naturaleza como en el devengo del jornal. Así, no cobraban lo mismo los trabajadores fijos de las explotaciones que los contratados por temporadas, a jornal o a destajo, siendo penalizada la estabilidad laboral con un menor salario. También había diferencias entre los trabajadores locales y los foráneos, ya que éstos, salvo expresa necesidad para su contratación, solían recibir menos paga $^{21}$. Y, por supuesto, existía discriminación salarial para con las mujeres y los menores, alegando su menor productividad. Del mismo modo, era costumbre descontar una parte del jornal a aquellos trabajadores que decidieran ir a pernoctar a sus casas, por el tiempo que perdían diariamente en ir y volver de la explotación ${ }^{22}$. Las diferencias salariales venían dadas, además, por el tipo de trabajo realizado, el cual no sólo dependía de los distintos cultivos (cereal, viña u olivar) sino de cada una de las tareas concretas que se tuvieran que realizar, tanto agrarias como ganaderas. En general, los trabajos mejor retribuidos eran los que precisaban una mayor cualificación o especialización, como por ejemplo los de poda en el viñedo y el olivar, o a los que se le exigía una mayor productividad, tal como ocurre con la siega ${ }^{23}$. Por otra parte, era normal que los jornales fluctuaran en consonancia con "la más o menos abundancia del año", es decir, que según las perspectivas de la cosecha se pagara más o menos ${ }^{24}$.

Pero los casos concretos se multiplican si tenemos en cuenta la forma en que se efectúa la remuneración. El aspecto fundamental de la misma radica en si ésta se realiza, exclusivamente, en metálico o si intervienen otros componentes en su cómputo final. No es extraño, por ejemplo, el que una parte o todo el trabajo realizado por los operarios del campo se abonara mediante la cesión de un trozo de tierra (peujal o senara) preparado para la siembra o incluso ya sembrado ${ }^{25}$. Esta práctica, que puede ser analizada tanto desde una perspectiva social, por la prepotencia de grupos socioeconómicos dominantes que imponen sus condiciones laborales, como desde un plano económico, en atención a un desarrollo deficiente y con carencias del sistema de producción capitalista, era bastante corriente, durante el siglo XVIII, en las localidades de la actual provincia de Cádiz. Diversas fuentes documentales, en especial escritos que denunciaban la mencionada costumbre por sus repercusiones negativas sobre las condiciones de vida de los trabajadores, así nos lo corroboran. Por ejemplo, el síndico personero de las tres localidades del Campo de Gibraltar exponía al Consejo de Castilla, en 1770, que los trabajadores agrarios de la zona acudían a...

\footnotetext{
"servir a los poderosos, y por tres meses que los ocupan en la sementera, sin otro salario, les siembra cuatro fanega de trigo, y esto poniendo el
}

21 En El Puerto de Santa María se acordó, en 1733, abonar a las cuadrillas que se contrataran en otras localidades los sueldos vigentes en sus lugares de origen, generalmente más bajos. Archivo Municipal de El Puerto de Santa María (A.M.P.S.M.), Leg. 1.605, 2-12-1733.

22 Este descuento significaba, en el año 1759 en El Puerto de Santa María, entre un 8 y un $12 \%$ del jornal diario. A.M.P.S.M., Leg. 1.630.

23 FLORENCIO PUNTAS, A. y LÓPEZ MARTÍNEZ, A.L.: "El mercado de trabajo...”, p. 82.

24 Dicha coletilla se incluye en las respuestas dadas por las localidades extremeñas en 1791. MELÓN, M.A.: Op. Cit., pp. 87-88.

25 Se trata de una práctica muy extendida, que podemos documentar en Italia, Cataluña, La Mancha o Extremadura. RUSSO, Saverio: Art. Cit., p. 78; ROCA FABREGAT, P.: Art. Cit., p. 81; DÍAZ PINTADO, J.: Op. Cit., p. 136 y MELÓN, M.A.: Op. Cit., p. 87. Sobre todo son beneficiarios los trabajadores fijos. 
pobre la simiente, no siendo esto lo peor, sino que lo ejecutan en las tierras más inferiores que tienen sus cortijos, de que dimana que solamente les rindan a dos o tres fanegas por simiente, de que se sigue verse precisados a esclavituarse" 26 .

Pero, lo más normal era complementar el pago en metálico con la manutención del trabajador o la entrega de determinados alimentos. Una encuesta realizada en 1791 en Extremadura ofrece datos interesantes sobre esta cuestión. Así, hasta en 119 localidades de un total de 169 , lo que representa un 70,4\%, los salarios relacionados con el cereal se componían de una parte abonada en dinero y de otra que consistía en el sustento o el aporte de productos alimenticios. Sólo en el 21,2\% de los casos la remuneración en metálico constituye la totalidad del abono del trabajador ${ }^{27}$. La partida de gastos por alimentar a los trabajadores constituía una parte sustancial del coste salarial de la explotación agrícola, entre un 40 y un $60 \%$, dependiendo de la menor o mayor presencia de trabajadores fijos o contratados por temporadas largas, que eran los que más se remuneraban por esta modali$\mathrm{dad}^{28}$, por lo que, en la medida que los precios de los productos agrarios se incrementaban se observa una tendencia a excluirlo de la paga ${ }^{29}$, aspecto nada fácil ya que estamos ante una costumbre muy arraigada, desde tiempos medievales (la anafaga), entre los empleados agrarios, a los que les costaría un gran esfuerzo conseguir esos productos en el mercado, por su escasez y carestía. Por ello, el trabajador parece aceptar con resignación un pago en alimentos que puede llegar a constituir hasta un $75 \%$ de su salario total, pero no debemos olvidar que en una sociedad en la que el hambre era una amenaza constante, asegurar, al menos, poder comer, era todo un logro, aunque fuera a costa de su trabajo íntegro. En otros casos, la entrega de algunos alimento se considera una adehala que complementa el sueldo. Así podemos considerar el vino que se facilita a los trabajadores de las viñas en la zona de Jerez, cuyo valor alcanza entre un 10 y un $15 \%$ del salario en metálico o las vituallas que se proporcionan a los destajeros de la siega ${ }^{30}$.

Por costumbre y, como ya vimos, por ley general desde el reinado de Enrique II, los concejos municipales estaban facultados para regular los salarios, prerrogativa que no dudaron en utilizar siempre que se producía, desde su propio punto de vista o a instancias de los empleadores, un aumento anormal de los jornales. En 1733 el gremio de cosecheros de viña de El Puerto de Santa María señalaba la necesidad de establecer reglas para "el mejor gobierno de los trabajadores y evitar los abusos hasta aquí practicados por ellos”, destacando como solían alterar " a su arbitrio los precios de los jornales con grave exceso y variedad”, acordándose por el cabildo formar una comisión para la redacción de las

Archivo Histórico Nacional (A.H.N.), Leg. 495, exp. 3.

27 MELÓN, M.A.: Op. Cit., p. 85. La alimentación de los trabajadores era habitual en distintas zonas geográficas. RUSSO, Saverio: Art. Cit., p. 78; ROCA FABREGAT, P.: Art. Cit., p. 81.

28 FLORENCIO PUNTAS, A. y LÓPEZ MARTÍNEZ, A.L.: "El mercado de trabajo...", p. 82, establece un 40\% en una finca con entre 10 y 16 trabajadores fijos. El 60\% se observa en una explotación con 30 operarios fijos, según PONSOT, P.: "Grand domaine et petite exploitation en Andalousie Occidentale: une étude de rentabilité comparative", en Congreso de Historia Rural, siglos XV al XIX, Madrid, 1984, pp. 168-169.

29 Un ejemplo en este sentido en BORRERO, M.: Op. Cit., pp. 244-246, que indica como se prohibe entregar vino a los gañanes entre enero y abril por ser caro y tenerlo que traer de otras localidades.

30 En El Puerto de Santa María se aportaba vino valorado en 24 maravedís, A.M.P.S.M., Leg. 1.630, año 1759. En Sanlúcar sólo por 17 maravedís, Archivo Municipal de Jerez de la Frontera (A.M.J.F.), Actas Capitulares (A.C.), cabildo, 30-8-1784, f. 460. 
mismas. En su punto $8^{\circ}$ establecía que los dos capitulares de cosechería se reunirían, el sábado al toque de oración, con los diputados del gremio y con los peones de mano institucionales, recién creados por la misma reglamentación, a fin de señalar los jornales que deberían regir en las distintas tareas de viña durante toda la siguiente semana ${ }^{31}$. No sabemos hasta cuando estuvo vigente esta norma, pero lo cierto es que, en 1759, de nuevo el gremio de cosechería se quejaba de unos salarios excesivos y arbitrarios, pidiendo que se tasaran. El concejo ordenó que el sábado o el domingo se estipularan por los veedores de viñas, empleos nombrados por el cabildo, los jornales de la semana, estando "asistidos" por los dos capitulares de cosechería, dos diputados del gremio y el síndico general. En este caso, la medida se llevó a cabo al menos durante un año, pues se conservan las actas de las reuniones ${ }^{32}$.

Unas actuaciones parecidas, igualmente promovidas por el gremio de cosechería, encontramos en Jerez de la Frontera. En 1732 se intento establecer una tasa de jornales, pero el Consejo de Castilla no prestó su conformidad. Algunos años después, en 1751, se dio un paso en este sentido al conseguir promover un salario de referencia, que resultaría de la media aritmética de los jornales pagados por los hacendados que tuvieran más de 12 aranzadas y 12 trabajadores contratados, el cual sería de aplicación para todos aquellos operarios que no se hubieran concertado durante el fin de semana. Por fin, en 1757, el gremio de cosechería obtuvo del Consejo de Castilla autorización para que se tasaran los jornales de viña a principio de cada mes $^{33}$, labor que recaería en el corregidor, asesorado por dos capitulares, aquellos que formaban parte de la junta de vinatería, aunque ello no fue óbice para que continuaran los desarreglos y disputas, por lo que, el 26-8-1767, la directiva de los cosecheros decidió suspender "la fijación del precio mensual dejando a todos en libertad para ver si el propio desorden los obligaba luego a pasar por los términos de la razón" ${ }^{34}$.

Desconocemos hasta que punto esta decisión del gremio de cosecheros de Jerez responde a una casualidad o si tenían conocimiento de lo que en esos momentos se estaba debatiendo en el Consejo de Castilla, ya que su acuerdo de dejar "libertad" coincide con la real provisión promulgada tres meses más tarde, el 29-11-1767, por la que "en cuanto a los salarios de los trabajadores se dejen en libertad para que cada uno se ajuste como pueda con los labradores y dueños de las tierras" "35. Según Artola esta ley era una solución de los ilustrados al problema jornalero, por la cual "se forzaba una negociación colectiva con los empresarios agrícolas que hasta entonces habían impuesto sus condiciones a través de los organismos municipales que controlaban" "36. Quizás hablar de negociación colectiva no sea la terminología más adecuada para el siglo XVIII, a lo sumo la norma podía ampliar la capacidad de concierto de las partes. Por otro lado, la defensa del jornalero es muy discutible, más bien nos encontramos, como apunta García

A.M.P.S.M., Leg. 1.605.

A.M.P.S.M., Leg. 1.630 .

A.M.J.F., A.C., cabildo 22-7-1757, f. 91. El real Despacho del Consejo fechado el 17-6-1757. Otro ejemplo de tasa en SÁNCHEZ LORA, J.L.: Capital y conflictividad social en el campo andaluz. Morón de la Frontera (1670-1800), Sevilla, 1987, pp. 78 y 79.

34 A.M.J.F.,A.C., cabildo 30-8-1784, f. 460.

35 Esta real provisión se incluye en una nota que acompaña la ley de tasa de los jornales de 1373 que se reitera en la Novísima Recopilación de 1805

36 ARTOLA, M.: Antiguo Régimen y revolución liberal, Barcelona, 1983, p. 51. 
$\mathrm{Sanz}^{37}$, ante intentos de favorecer a los labradores mediante una normativa que modifique las anquilosadas relaciones de producción que regían la actividad agrícola. Así, la liberalización de los salarios coincide con las medidas de libertad de comercio de granos, de supresión de derechos aduaneros o de los privilegios de la Mesta. De lo que significó esta ley para sus coetáneos sólo tenemos, ya que una vez más los jornaleros aparecen mudos, la opinión de los hacendados, los cuales se mostraron muy críticos con ella, puesto que rompía con procedimientos muy arraigados y ponía en peligro la estabilidad social. Así, en el cabildo de Jerez se manifestaba por los regidores, componentes genuinos de las familias propietarias y arrendadoras de tierras, que dicha orden traía la insolencia de los trabajadores, numerosos pleitos y contiendas que ni siquiera la justicia podía someter, por lo que "venía a estar hecho el pueblo un problema sobre el particular”. Por su parte, los diputados del común, cargos electos y en ocasiones contrarios de los regidores, defendían la libertad de concertación salarial establecida, aunque sus motivos fueran más prácticos que altruistas, al señalar que si a los trabajadores "se les coartase la libertad de ajustarse como pudieren tomarían el efugio de irse a emplear a otros trabajos que más le acomodasen con abandono de las viñas”. La necesidad de empleados se impone a las reticencias contra la normativa ${ }^{38}$.

Tras los juicios de valor, las autoridades locales, eco de los empleadores, pasaron a la acción e intentaron, con más o menos éxito, restablecer los jornales tasados, sobre todo en una época, 1770-1800, de subida constante de los salarios. En 1784 el ayuntamiento de Jerez proponía que el gremio de cosechería de la localidad, en unión con los de El Puerto y Sanlúcar, acudiera al Consejo de Castilla con la mencionada pretensión. El gremio portuense, en 1800, instaba al concejo municipal para que procediese a tasar los jornales, alegando que la ley del siglo XIV que otorgaba dicha facultad a los gobiernos locales se encontraba vigente, ya que la jurisprudencia advierte que "la ley no derogada se guarde, cumpla y ejecute según su literal contexto sin que pueda alegarse el no uso", claro esta que se "olvidaban" de un pequeño detalle, la real provisión de 1767 tampoco estaba derogada ${ }^{39}$.

Las insuficiencias de la normativa y contradicciones de los tribunales ${ }^{40}$ en cuestión salarial, junto a los intereses de autoridades y empleadores, y frente a las reclamaciones de los trabajadores, propiciaban, como más adelante comprobaremos, constantes disputas y conflictos.

Otro aspecto interesante de la regulación laboral era el referido a la duración de la jornada de trabajo. El uso y la costumbre habían impuesto una jornada de "sol a sol”, es de-

37 GARCIA SANZ, Angel: "La reforma agraria de la Ilustración: proyectos y resultados. El precedente del arbitrismo agrarista castellano", en GARCIA SANZ, A. y SANZ, J.: Reformas y politicas agrarias en la historia de España, Madrid, 1996, pp. 161-200.

38 Las opiniones de unos y otros cargos jerezanos en A.M.J.F., A.C., cabildo 30-8-1784, f. 258.

39 Estos ejemplos en A.M.J.F., A.C., cabildo, 30-8-1784, f. 460, y A.M.P.S.M., A.C., cabildo 29-3-1800, f. 96.

40 En 1788 el Consejo de Castilla rechazaba un intento de tasar los jornales planteado por varios pueblos de la Mancha, alegando que el salario "era el único patrimonio de los jornaleros y braceros", DÍAZ-PINTADO, J.: Op. Cit., p. 137. Por su parte, DOMINGUEZ ORTÍZ, A.: "Dos pleitos sobre tasa de jornales agrícolas" en DOMINGUEZ ORTÍZ, A.: Estudios de Historia económica y social de España, Granada, 1987, pp. 203-210, señala una sentencia favorable de la Chancillería de Granada a la tasa de jornales, en 1777, olvidando la real provisión de 1767, a instancias de la villa de Hinojosa del Duque (Córdoba). 
cir, los trabajadores deberían salir para las haciendas al alba, a la primera luz del día, y tomar el camino de regreso de tal forma que llegaran a la localidad al anochecer. Dado que tanto el amanecer como la puesta del sol son momentos algo indefinidos había que establecer un principio de autoridad al cual sujetarse, para lo que se recurre a la Iglesia. El toque de campana del alba, recordando el rezo del avemaría, marcaría el inicio de la marcha; mientras que el toque de oración, en la tarde noche, debería ser escuchado por los trabajadores al entrar, de regreso, en la localidad ${ }^{41}$. Esto se entiende, respectivamente, los lunes y los sábados, ya que el resto de los días, al pernoctar los operarios en las explotaciones, el trabajo era completo de sol a sol, sin pérdidas por los desplazamientos. Pero, esta regla general, precisamente por estar sometida a la costumbre, presenta múltiples variaciones dependiendo de cada lugar, de las diferentes tareas agrícolas e, incluso, de los descansos permitidos dentro de la jornada laboral. Por ejemplo, la estructura de un día de trabajo en Sanlúcar de Barrameda en la segunda mitad del siglo XVIII era la siguiente: los trabajadores se encaminarían para las haciendas antes de salir el sol; al llegar "se les dará una hora de descanso para que almuercen y no más”; luego comenzará el trabajo, sin descanso, hasta las doce del mediodía; se parará hasta la una para comer; y se continúa trabajando hasta que se ponga el sol, si se duerme en la hacienda, o hasta la hora límite que permita al operario regresar a la localidad para estar en ella al toque de oración. Este horario se modificaba del 1 de mayo al 29 de septiembre, por permitirse "una hora más al mediodía para descanso después de comer por siesta, a causa de las calores del verano”. Precisamente, la temporada estival, por su mayor número de horas de sol, es la que presenta una casuística más amplia, que va desde reducciones de jornadas ${ }^{42}$, refutadas por los empleadores, a ampliaciones del número y duración de los descansos, algo que, como hemos podido comprobar, era una cuestión admitida ${ }^{43}$.

La normativa laboral también refleja su preocupación ante una oferta de mano obra escasa, lo cual no sólo repercute en un incremento de los salarios sino que puede poner en peligro las cosechas. Por ello, encontramos disposiciones en las que no se duda en coartar la libertad de movimientos y de concertación de los trabajadores al prohibirles irse a otros lugares a trabajar mientras hubiera necesidad de ellos en la propia localidad. Del mismo modo, se establecen sanciones y, sobre todo, se amenaza con aplicar las provisiones contra vagos a todo aquel trabajador que, habiendo ocupación, se encontrase ocioso ${ }^{44}$. Finalmente, se conminaba a los individuos que realizaban actividades, no adecuadas desde el punto de vista de los empleadores, como la rebusca o la reventa. Así, en 1783 las autoridades locales de Jerez de la Frontera se hacían eco del desorden que significaba,

"el hallarse empleados porción de trabajadores, de la edad robusta e inteligencia competente para las labores del campo, en el débil ministerio de estar vendiendo en las esquinas de las calles y plazas porción de higos,

41 Un ejemplo de este uso de los toques litúrgicos, en la ciudad de Plasencia, en MELÓN, M.A.: Op. Cit., p. 85 .

42 BORRERO, M.: Op. Cit., pp. 235-242, señala como a finales de la Edad Media se permitía trabajar sólo medio día a partir del mes de abril y hasta el final del verano.

43 MELÓN, M.A.: Op. Cit., p. 86, señala como en Badajoz, en verano se permitía un descanso de tres horas al mediodía, muy superior al visto para Sanlúcar.

44 En Morón, en 1682, la sanción era de 1.000 maravedís y 6 días de cárcel, SÁNCHEZ LORA, J.L.: Op. Cit., p. 80. En Jerez, el trabajador no empleado sería reputado por vago, A.M.J.F., Leg. 171, exp. 5310, año 1782. 
que llaman de tuna, ejercitándose en una vida holgazana y propiamente de sujetos vagos".

Lo que llevó al corregidor de la ciudad a emitir un auto por el que se prohibía la venta ambulante de higos de tuna y otras frutas, salvo a "aquellos hombres que se hallen en la edad de 60 años o con enfermedad habitual que les impida el trabajo en las labores del campo, y a los muchachos hasta la edad de 12 años", es decir, los no aptos para ocuparse en las tareas agrícolas ${ }^{45}$.

Un ultimo aspecto nos queda por tratar sobre la normativa laboral: el de los contratos de trabajo. Por norma general, los acuerdos suelen ser orales, aunque desde fechas tempranas se aprecia el recurso al contrato por escrito ante notario. Esta tipología se utiliza en la contratación de guardas o caseros y, sobre todo, en la de destajeros para la siega o la recogida de la aceituna. La realización de un contrato escrito permite rellenar las lagunas de la normativa; asegura, generalmente incluyendo algún adelanto pecuniario, la permanencia del trabajador; y abarata los costes de la supervisión al estar delimitadas en el contrato la cantidad y calidad del trabajo a efectuar ${ }^{46}$. No habría que olvidar la acentuación de la coacción ejercida por el empleador al contar con una prueba de cargo escrita que puede ser presentada a las autoridades administrativas y judiciales ante cualquier controversia que pudiera surgir.

No obstante, como ya hemos dicho se imponía el contrato oral. El patrón, directamente o través de su capataz, concierta la jornada o temporada de trabajo con cada operario particular o con un manijero o jefe de cuadrilla ${ }^{47}$. Estos contratos orales, a pesar de que en ocasiones se acompañaban de un anticipo del salario para hacerlos más firmes, eran muchas veces quebrantados por los trabajadores del campo, que no dudaban en acomodarse con otro labrador si se le ofrecían mejores condiciones laborales. Esta práctica debía ser muy habitual, como lo demuestra el hecho de que las autoridades locales reiteraran las disposiciones que la censuran y decretan duras sanciones para los infractores, ya sean los operarios que abandonan el trabajo como los empleadores que los contratan. En Jerez de la Frontera, en 1769, se estableció una multa de 44 reales, equivalente a unos diez días de salario; pero, a partir de 1775, la sanción se cambió por diez días de cárcel, medida que es recordada varías veces en la década de $1780^{48}$.

En resumen, una amplia normativa reguladora del trabajo asalariado agrícola que, emitida por las autoridades municipales, tiene como objetivo controlar el mercado de trabajo en cada localidad concreta, siempre en beneficio del grupo de los grandes labradores, generalmente relacionados personal o económicamente con los miembros del gobierno

45 A.M.J.F., Histórico Reservado, cajón 6, no 30, ff. 587-588. Auto de 21-8-1783. Medidas muy parecidas en la localidad de Almagro, en 1786, DÍAZ-PINTADO, J.: Op. Cit., p. 138.

46 Sobre estos aspectos, BORRERO, M.: Op. Cit., pp. 216-220 y FLORENCIO PUNTAS, A. y LÓPEZ MARTÍNEZ, A.L.: "El mercado de trabajo...", pp. 70-73.

47 La figura del manijero, peón de mano o cuadrillero, nexo de unión entre el empleador y los trabajadores, e individuo que negocia las condiciones laborales del grupo, resulta tan significativa que no faltaron los intentos para reglamentarla. Así, en 1733, en El Puerto se ordenó que los peones de mano deberían ser nombrados por el gobierno local, A.M.P.S.M., Leg. 1.605. En Jerez, en cambio, en 1751 se dio un edicto del corregidor prohibiendo los peones de mano, bajo multa de 4 ducados, y obligando a cada trabajador a concertarse por sí mismo, A.M.J.F., Histórico, cajón 24, exp. 42.

48 A.M.J.F., leg. 171, exp. 5.307 e Histórico Reservado, cajón 6, nº 30, ff. 476-477. 
local, y recalcando, no los derechos, sino las obligaciones del trabajador del campo. La rigidez y la parcialidad de estos ordenamientos laborales darán lugar, con bastante frecuencia, a la queja, cuando no al incumplimiento de los mismos, aunque, por lo general, ello se llevara a cabo de forma soterrada y sin mucha estridencia, lo que repercute en esa visión, ya comentada, de falsa paz laboral.

Pero, a pesar del interés de empleadores y autoridades locales por reglamentar el desarrollo del trabajo asalariado en el campo, es palpable como las contrataciones y las condiciones laborales vienen determinadas, cada vez de forma más clara, por dos factores preponderantes. El primero de ellos exógeno, que viene dado por la evolución demográfica, la cual marca la oferta de operarios. El otro endógeno de la propia actividad agrícola, nos referimos a las necesidades y ritmos de los cultivos y de los sistemas de explotación de la tierra, que marcan la demanda de trabajadores.

El siglo XVIII fue un periodo de crecimiento demográfico en España, al menos desde la finalización de la guerra de Sucesión. Se trata de un incremento relativamente moderado, en torno al 0,42\% anual entre 1717 y 1797, pero, lo que es más significativo, con una continuidad inusitada en la evolución demográfica española durante la Edad Moderna. Este aumento de la población durante el siglo XVIII no afecta por igual a todos los grupos sociolaborales, manifestándose, en especial, una fuerte subida de los elementos trabajadores y, entre estos, dada la preponderancia de la actividad económica agraria, son los operarios del campo los que presentan un mayor incremento de sus efectivos.

No es fácil seguir la evolución demográfica de los trabajadores agrícolas en el siglo XVIII, ya que las fuentes documentales que hacen referencia a la situación laboral son escasas, correspondiendo la mayoría a la segunda mitad de la centuria. Y, además, nos encontramos con un doble problema. O bien se obvia el computar en las encuestas a una parte importante de los asalariados del campo por el carácter estacional de su empleo, o se engloban en el concepto amplio de jornalero, que sería todo aquel trabajador no fijo contratado por jornadas ${ }^{49}$. El Catastro de Ensenada, realizado en la década de 1750, establece, aproximadamente, en 400.000 el número de jornaleros existentes sólo en Castilla. En el censo de Floridablanca, en 1787, con datos referidos al conjunto nacional, los jornaleros contabilizados son ya 964.571 , de los cuales 698.749 corresponden a territorio castellano. En esta última zona, en la que es posible la comparación, se registra, entre 1755 y 1787, un notable incremento, cuantificado en torno al 75\%. Por último, el censo de Godoy, de 1797, quizás por su mayor minuciosidad, al establecer nuevas categorías laborales, reduce el número de jornaleros, en toda España, a $804.183^{50}$.

49 Estos problemas de las fuentes comentados por EIRAS ROEL, A.: "Sobre la distribución profesional de la población en la España de Carlos III. Examen crítico de las cifras censales”, en Coloquio Internacional Carlos III y su siglo, tomo II, pp. 505-543. BERNAL, A.M.: La lucha por la tierra en la crisis del Antiguo Régimen, Madrid, 1979, p. 390, indica que, en ocasiones, ser "del campo" era sinónimo de carecer de oficio determinado.

50 Estos datos obtenidos de MATILLA TASCÓN, A.: La única contribución y el Catastro de la Ensenada, Madrid, 1947; Censo español ejecutado de orden del rey comunicada por el Excelentísimo señor Conde de Floridablanca en el año de 1787, Madrid, 1787, edición facsímil, Madrid, 1981; CANGA ARGÜELLES, J.: Diccionario de Hacienda con aplicación a España, Madrid, 1834, edición facsímil, Madrid, 1968, tomo II, p. 9. Reseñar la confusión existente con respecto a la diversa información aportada por el conjunto documental del Catastro de Ensenada. Según los resúmenes el número de jornaleros es de 301.199, sin contabilizar los de Murcia y Sevilla, que serían unos 80.000. Por otra parte, el Vecindario de Ensenada señala hasta 627.421 vecinos jornaleros ¿agrícolas?. 
El aumento demográfico del grupo sociolaboral de los trabajadores agrícolas, aunque general en todo el territorio, presenta en la zona meridional de la península una mayor relevancia. Así, por ejemplo, en el reino de Sevilla, que comprende las actuales provincias de Sevilla, Cádiz, Huelva y parte de Málaga, se computan en el Vecindario del Catastro de Ensenada (1759) un total de 60.566 vecinos jornaleros, cifra que habría que aumentar en torno a un $20 \%$ para incluir a los trabajadores del campo que por distintas razones, como ser hijos o dependientes de otros, no tenían la condición de vecinos ${ }^{51}$. Treinta años después, el censo de Floridablanca contabiliza hasta 119.534 jornaleros en el reino sevillano, lo que significa un incremento porcentual que oscilaría entre el 58 y el 98\%, según si hemos corregido o no al alza la cifra inicial de 1759. El censo de Godoy, al contrario de lo que ocurre en el resto de los territorios, no señala un descenso brusco del número de jornaleros, que se mantiene en 118.741, por lo que en esta zona andaluza está claro que el “jornalero" es esencialmente un asalariado del campo.

El incremento tan sustancial de los trabajadores del campo responde a varias razones. Por supuesto, las puramente demográficas, el mayor número de asalariados va en consonancia con la evolución al alza de la población en general. Pero hay otros factores que conviene resaltar. Así, la estructura de la propiedad de la tierra, en la que se observa como la mayor parte de la superficie se concentra en unas pocas manos, con el agravante de la vinculación, que impide su salida al mercado. Un ejemplo de esta situación nos lo ofrece la ciudad de Jerez de la Frontera, donde sobre un total de 120.461 hectáreas que componían el término (datos del Catastro de Ensenada) sólo el concejo municipal administraba, como tierras de propios y comunales, hasta $49.886 \mathrm{Ha}$.; entre las diversas instituciones eclesiásticas destacan 18 conventos que poseían otras 7.489 Ha.; y las 54 familias nobles que copaban el gobierno local eran dueñas de 29.140 Ha.. Es decir, 69 propietarios monopolizaban el $72 \%$ del terrazgo. El panorama se completa si añadimos que el porcentaje de tierras vinculadas, por seglares, Iglesia y municipio alcanzaba hasta el $86 \%$ del conjunto del agro jerezano ${ }^{52}$. La falta de tierra libre y las dificultades para obtenerla en arrendamiento, pues los propietarios prefieren a los grandes arrendatarios, obligan a muchos pequeños campesinos a convertirse en asalarariados.

Por otro lado, no hay ningún interés por parte de las autoridades locales, a pesar de las recomendaciones del ilustrado gobierno central, en fomentar otras actividades económicas, como las manufacturas, ya que ello podría implicar una peligrosa disminución de la mano de obra disponible para las faenas agrícolas, lo que repercutiría no sólo en el incremento de los costes salariales sino en el propio desarrollo agrario, el cual, a falta de avances técnicos, se debe, exclusivamente, a la extensión de la superficie cultivada y de un número mayor de operarios disponibles.

51 Si se comparan los datos de vecinos jornaleros del Vecindario con los que ofrecen, referidos a trabajadores individuales, los libros de familia del Catastro, se obtiene esa diferencia, al alza, en torno al 20\%. La información sobre los jornaleros agrícolas de distintos pueblos del Reino de Sevilla según los libros de familia en BERNAL, A.M. - COLLANTES, A. - GARCÍA BAQUERO, A.: "Sevilla de los gremios a la industrialización", Estudios de Historia Social, 5-6 (1978), p. 74.

52 Estos datos en A.M.J.F., Memoranda 4, pp. 86-95; GONZÁLEZ BELTRÁN, J.M.: Honor, riqueza y poder. Los veinticuatros de Jerez de la Frontera en el siglo XVIII, Jerez de la Frontera, 1997, p.72 y del mismo autor: "Patrimonio y rentas de los conventos de Jerez de la Frontera a fines del Antiguo Régimen", en Panfletos y materiales. Homenaje a Antonio Cabral Chamorro, historiador (1953-1997), Trebujena, 1998, p.306. 
En general, y a pesar del incremento de trabajadores expuesto, se detecta, al menos en la segunda mitad del siglo XVIII y en las localidades con una fuerte expansión agrícola, una escasez de asalariados del campo, que se hace sobre todo patente en determinadas tareas que requieren un gran número de efectivos, tales como las escardas o las recolecciones (siega, vendimia, recogida de la aceituna). Estas carencias de la oferta de mano de obra local eran subsanadas, en parte, recurriendo a trabajadores foráneos, generalmente de localidades cercanas, pero también provenientes de otras zonas que exigían largos desplazamientos. Un memorial de un particular remitido al concejo de Jerez nos informa sobre estas necesidades de asalariados foráneos y el origen geográfico de los mismos. Indica, que acuden a Jerez multitud de trabajadores forasteros que ayudan a todos los trabajos de sus campiñas. Así, para la siega “cuadrillas numerosas de serranos”, que son vecinos de las localidades de la Sierra de Cádiz, la mayoría de ellas colindantes, por su parte noreste, con el amplísimo término jerezano. Para las faenas de arada y cava se cuenta con temporeros de los municipios de Lebrija y Trebujena, dos localidades de la campiña cercanas a Jerez. La recolección de las semillas (habas, garbanzos y arvejones) y de la aceituna la llevan a cabo, sobre todo, "los que nombraban antes gitanos", que sin domicilio fijo se trasladaban de pueblo en pueblo para obtener, a través de variadas actividades, su sustento. Por último, se indica que "los más de los ganaderos son gallegos", se refiere a los empleados en el cuidado del ganado de labor ${ }^{53}$.

La descrita insuficiencia, general o puntual, de trabajadores será un elemento a tener muy en cuenta para entender las posibilidades de concertación laboral y las condiciones más o menos favorables en las que ésta se lleva a cabo. En especial si, como ocurre en el siglo XVIII, la demanda de mano de obra agrícola parece incrementarse notablemente favorecida por la diversidad y extensión de los cultivos.

En esta línea, por ejemplo, el desarrollo del viñedo, constatado en muchas localidades gaditanas, conlleva un aumento muy substancial de la necesidad de trabajadores, por un hecho muy sencillo, el cultivo de la vid precisa mayores cuidados y, por tanto, el número de jornadas de trabajo se incrementa. Una hectárea de viña requiere en torno a 110 jornales al año, los mismos que permiten labrar, al tercio, hasta 7 hectáreas de cereal ${ }^{54}$. Del mismo modo, la roturación y puesta en cultivo de pastizales y tierras baldías, demanda el correlativo incremento de trabajadores. Un ejemplo nos ayudará a captar esta cuestión con mayor nitidez. En Jerez de la Frontera, en torno a 1755, había 19.211 Ha. sembradas de cereal (que se corresponden con $56.515 \mathrm{Ha}$. de cultivo al tercio), que a 43 jornales cada una resultan 826.073 jornadas de trabajo. Es decir, se precisan unos 4.000 asalariados que trabajan, por término medio, unas 200 jornadas. En 1817, tras la venta y conversión en tieras de sembradura de varias propiedades comunales baldías, el número de hectáreas sembradas de cereal se ha incrementado hasta las 23.915, a las que aplicando las mismas reglas,

53 A.M.J.F., A.C., cabildo 8-8-1785, ff. 258-260. Sobre el recurso a trabajadores foráneos FLORENCIO PUNTAS, A. y LÓPEZ MARTÍNEZ, A.L.: "El trabajo asalariado...”, p. 109.

54 En concreto una hectárea de cereal, cultivada al tercio, lo que significa que hay otra hectárea en barbecho y otra preparándose, requiere 43 jornales. Por su parte, una hectárea de olivar precisa 22,5 jornales. Cálculos propios utilizando información aportada por documentos del Archivo de Jerez, A.M.J.F., A.C., cabildo 8-8-1785, ff. 258260 y Beneficencia y hospitales, libro 48. Y datos tomados de FLORENCIO, A. y LÓPEZ MARTÍNEZ, A.L.: "El trabajo asalariado...", pp. 102-108. También, sobre el cultivo del cereal, CANGA ARGÜELLES, J.: Op. Cit., p. 34. Y de gran interés los cálculos proporcionados por PONSOT, P.: "Grand domaine et petite exploitation...", pp. 161-172, que utiliza la memoria realizada por un labrador de Aguilar de Córdoba en 1789. 
necesitarían 1.028.333 jornales para su cultivo o, lo que es lo mismo, el trabajo de unos 5.150 operarios $^{55}$.

Pero la demanda de mano de obra no sólo es alta y en aumento sino que, además, al estar sometida a unas necesidades y ritmos muy precisos y específicos, presenta una fuerte concentración en determinados periodos del ciclo agrario. Cada cultivo requiere unas tareas concretas que, y esto es muy significativo, deben desarrollarse en unas fechas determinadas y en un tiempo delimitado. Por ello, el número de operarios a contratar no sólo depende de la superficie de la explotación sino del plazo temporal del que se disponga para realizar la tarea correspondiente. Con mayores efectivos de asalariados los trabajos agrícolas se harán de forma más diligente, evitando los riesgos de una climatología adversa que ponga en peligro los cultivos y su cosecha.

Es este fuerte empeño por hacerse con el mayor número de trabajadores en periodos puntuales lo que actúa como el elemento que distorsiona las restrictivas normas laborales y amplia el marco de concertación de los operarios del campo. Y ello, de forma especial, en aquellos lugares en los que el capital es utilizado, por las reducidas manos que lo acaparan, como un instrumento que facilita la captación de asalariados, menospreciando las limitaciones impuestas por las tasas de los jornales. Las quejas contra estas prácticas capitalistas, por entenderlas como "abusivas" y "contrarias a los usos tradicionales", se detectan de forma continua en la documentación. Los diputados del común de Jerez enviaban, en 1767, un memorial al Consejo de Castilla denunciando el predominio de las grandes explotaciones y, entre los males que éstas generan, destacan...

"el perjuicio que los acaudalados suelen causar llevándose los más de los jornaleros que concurren a la pública plaza, por EL CRECIDO PRECIO que suelen ofrecerles, lo que es daño conocido de los pobres pelentrines (pequeños labradores) que no pueden darles el mismo por los cortos útiles (...) que les queda de su labor y tráfico (...). Quedándose por esta razón sin trabajadores o esperando para hacer sus faenas el que dichos acaudalados acaben las suyas ${ }{ }_{66}$.

En 1784 el gremio de cosecheros de Sanlúcar se reitera en dicha posición al recalcar que la causa de los altos jornales que se pagaban,

"viene de la libertad que cada dueño de viña tiene en mandar a sus capataces cojan gente a CUALQUIER PRECIO para evacuar sus faenas, unas veces impulsados de sus mismos capataces, otras validos de SUS FONDOS CRECIDOS, sin considerar el daño común que originan a la causa o bien universal del cuerpo" ${ }^{57}$.

Para paliar los efectos negativos de estas prácticas se procedió a restituir la vigencia de las antiguas leyes medievales que limitaban el número de jornaleros que podían ser con-

55 Los datos de 1755 del Catastro de Ensenada y los de 1817 del Censo de Garay, ambos tomados de A.M.J.F., Memorandas 4 y 2, pp. 95 y 172 respectivamente.

56 El memorial en Archivo Histórico Nacional (A.H.N.), Consejos, leg. 1840, pieza 3, f. 47.

57 A.M.J.F., A.C., cabildo 30-8-1784, f. 460. Del mismo modo, las autoridades de Hinojosa del Duque, al solicitar, en 1777 , la tasa de jornales, argumentaban que "era preciso proveer de remedio en el particular, conteniendo la ambición de los adinerados". DOMÍNGUEZ ORTÍZ, A.: "Dos pleitos...”, p. 207. 
tratados por cada labrador, a no más de 12, y, además, se dispusieron fuertes multas contra los transgresores, a pesar de lo cual no se impidió que el capital impusiera su dictado y fuera regulando, al margen de las restricciones normativas, el mercado de trabajo.

$\mathrm{El}$ incremento global de la demanda de asalariados, la carencia puntual de jornaleros para determinadas tareas y la intervención del capital en el mercado laboral debieron de incidir en un auge de las reclamaciones de los trabajadores del campo y en la obtención por éstos de mejoras en sus condiciones de trabajo.

\title{
3. CAUSAS Y MANIFESTACIONES DE LA PROTESTA LABORAL EN EL MUNDO RURAL
}

Como ya comentamos en la primera parte de este trabajo, la impresión que nos ha sido transmitida a través de la escasa bibliografía que ha tratado el tema, es la de un mundo laboral agrario en el que la protesta y el conflicto no suelen prodigarse. Igualmente, hemos señalado que esa imagen casi idílica de paz y concordia no es el reflejo exacto de una realidad en la que las reclamaciones y quejas son una constante en las relaciones laborales. Así lo atestigua, en 1785, un eclesiástico anónimo de Jerez de la Frontera, que escribía:

\begin{abstract}
"Y si a esto se añade la desavenencia constante, que vemos entre mercenarios (trabajadores) y conductores (empleadores), ¿qué progreso podrá esperar la agricultura?. Estos dos partidos jamas se han podido reconciliar, a pesar de todos los moralistas, ni se reconciliarán mientras los políticos no extirpen la raíz de su miserable discordia (...), su fidelidad rara vez pasará de la apariencia y su unión casi siempre será precaria, porque todos deseamos lograr más a menos costo" 58 .
\end{abstract}

Otra cuestión es que, por diversos motivos, esas protestas no hayan tenido un eco proporcionado en la documentación. En ello puede incidir el propio interés de las autoridades por ocultar una problemática que, quizás, este generada o no solventada adecuadamente por su propia incompetencia. Por otro lado, estaría la actitud de los trabajadores, reacios, por convencimiento propio, modelado durante siglos por un adoctrinamiento religioso y social, o por miedo al correctivo y a la represión gubernativa y judicial, a mostrar abiertamente su contrariedad y a recurrir a medios "muy ostensibles" para conseguir sus reivindicaciones. Se impone, en muchos casos, el recurso a la humilde solicitud, buscando una respuesta caritativa, o hacer uso de prácticas de resistencia encubierta.

A lo largo de las páginas anteriores hemos ido exponiendo cuales eran las reglas y condiciones laborales de los trabajadores del campo en la Andalucía del siglo XVIII, y se recalcaba como el rechazo y el incumplimiento de las mismas era causa continua de conflicto. En especial, tres eran los motivos contractuales que originan las mayores desavenencias: la duración de la jornada laboral, el incumplimiento de los contratos y, por supuesto, la estipulación del salario. En cuanto a la jornada laboral, los trabajadores defienden que se mantengan las "costumbres" plenamente aceptadas. En esta línea, el operario no se muestra contrario a la larga jornada de "sol a sol", pero si se opone a los inten-

${ }_{8}$ Perjuicios de la vinculación y ventajas de la libertad de los caudales, Jerez de la Frontera, 1785, pp. 45-46. 
tos de los empleadores de aumentar la productividad reduciendo los tiempos tradicionales de traslado y descanso e incrementando el ritmo de trabajo. Ello venía a romper una especie de acuerdo tácito, por el cual el labrador imponía el salario y el trabajador establecía, dentro de unos márgenes admitidos, la intensidad de su trabajo. Si el empleador quería un mayor rendimiento debería de recurrir a "destajeros" que recibían una mayor remuneración.

Por su parte, la rotura de los compromisos de trabajo y las peticiones de subida de salario tienen una misma finalidad: aumentar los ingresos en consonancia con el alza generalizada de los precios de los productos de subsistencia. Y ello, de forma especial durante el siglo XVIII, sobre todo su segunda mitad, que es un periodo de fuerte inflación, intentando los trabajadores con la subida de salario mantener, al menos, su escaso nivel adquisitivo. El debate que se plantea es por el denominado "salario justo", cuya idea no es la misma para los operarios que para los empleadores. Los primeros, plantean como "salario justo" aquel que se adapta a los precios de los mantenimientos, y que permite alimentarse al trabajador y a su familia, sobre todo si se tiene en cuenta que éste tiene gastos durante todo el año pero no siempre se encuentra empleado. Por su parte, los empleadores, como los labradores de Córdoba, en 1755, que se quejaban de que los segadores y otros trabajadores del campo pedían "por su trabajo excesivos e irregulares precios sin poderse conseguir se arreglen a lo justo" 59 , mantienen que ese "lo justo" viene determinado por las expectativas de la cosecha y por la exigencia de no incrementar, mediante cualquier subida salarial, los costes de su explotación. Desgraciadamente para los operarios del campo, la mayoría de las veces las autoridades que tenían que discernir sobre estas dos concepciones del "salario justo" se encontraban más cercanas a las posiciones de los grandes labradores, a los que no dudan en respaldar. Sin apoyo de la justicia, a los trabajadores sólo les queda resignarse o recurrir a medidas contrarias al orden establecido.

A estas causas laborales de protesta, podemos añadir otros dos motivos de conflicto planteados por los trabajadores del campo. El primero tiene su origen en la falta de trabajo durante determinadas épocas del año, ya sea por las condiciones climatológicas adversas (lluvias o sequías), por cuestiones técnicas (periodos en los que los cultivos no precisan tarea alguna) o por decisión empresarial (no realizar determinadas faenas al objeto de abaratar los costes $)^{60}$. Está contrastado que, en el siglo XVIII, el jornalero agrícola, a excepción del escaso personal fijo, sufría periodos regulares de desempleo que oscilaban entre los dos y los cuatro meses, llegando hasta los seis en el caso de que, por pérdida de los cultivos o por reducir gastos ante una cosecha deficitaria, se suprimieran las escardas primaverales. En la segunda mitad de dicho siglo, el aumento de jornaleros ya comentado, necesario para atender los momentos álgidos del ciclo agrícola, provoca, por otra parte, serios problemas de orden público al concentrarse en las localidades gran número de trabajadores sin empleo en los llamados "meses mayores" (febrero-mayo), es decir, aquellos en los que los precios de los cereales, y por lo tanto del pan, alcanzan su nivel más elevado, sobre todo si las expectativas de la próxima recolección no son buenas. Los operarios del campo, sin trabajo y sin dinero, solicitan a las autoridades e instituciones que les

Citado por CORTÉS PEÑA, A.: Op. Cit., p. 52.

60 Sobre estos aspectos BERNAL, A.M.: La Lucha por la tierra en la crisis del Antiguo Régimen, Madrid, 1979, p. 419. Un trabajador no solía estar empleado más de 200 días laborables. Lo mismo ocurría en Francia. LABROUSSE, E.: Fluctuaciones económicas e historia social, Madrid, 1962, pp. 255-256. 
socorran, y en el caso de no ser atendidos en su, de nuevo, “justa reivindicación”, no dudan en recurrir a prácticas intimidatorias y-o ilícitas.

El último motivo de conflicto viene generado por la normativa estatal, dictada entre 1766 y 1770, relativa a los repartos de tierras de labor municipales de propios y arbitrios entre los jornaleros y pequeños labradores ${ }^{61}$. Las autoridades locales encargadas de ponerla en ejecución no actuaron de forma correcta, entorpeciendo o desvirtuando su aplicación, casi siempre en beneficio de los grandes labradores y ganaderos. Aunque de forma limitada, y en la mayoría de los casos unidos a los pequeños agricultores, los jornaleros llevaron a cabo acciones de reclamación con la intención de verse incluidos en los repartos o para recuperar las suertes que les habían correspondido y de las que habían sido, por diversos motivos ciertos o supuestos, desahuciados.

Las causas de conflicto aquí enumeradas presentan entre ellas diferencias tanto en cuanto al número de veces que se reiteran como a la cronología en la que aparecen. La documentación consultada y los datos aportados por la bibliografía ${ }^{62}$ nos indican que es la cuestión de los salarios la que más disputas genera, en torno al 50\% de todos los casos de conflictividad, manteniéndose en el mismo nivel porcentual tanto durante la etapa de 1745-1775 (52,9\%) como en la siguiente de 1776-1805 (48,3\%). A continuación, aparecen los problemas originados por el desempleo estacional de los trabajadores, que acaparan el $21,7 \%$ del total de los conflictos. En el caso de esta tipología, se observa un incremento porcentual significativo entre el primer periodo, con un $17,6 \%$, y el segundo, donde se llega al $24,1 \%$, está claro que el aumento de trabajadores, muy visible en las paradas agrícolas, no tiene efecto hasta la década de 1770. Las desavenencias por la duración de la jornada laboral alcanzan el 17,4\% de todos los conflictos, dándose aquí una evolución contraria a la de los problemas por el paro, ya que, porcentualmente, se observa un descenso en el periodo 1776-1805, con un 10,3\%, cuando en la etapa anterior se llegaba al 29,4\%. Por último, los conflictos por los repartos de tierra, dada la propia cronología de las leyes, se concentran en el periodo 1776-1805, donde se contabilizan el 17,2\% de todas las reivindicaciones, cuando su total para toda la etapa estudiada sólo es del 10,9\%. Un último dato, las manifestaciones en general de protesta o de queja se incrementan sobre todo en las dos décadas finales del siglo XVIII, contabilizándose hasta un 70\% más de casos que en el periodo de $1745-1775$.

La protesta, la queja o la reclamación por parte de los trabajadores suele manifestarse de diversas formas, pero en líneas generales presenta unas características similares. Así, ante los estrechos límites de negociación que les deja la reglamentación laboral y el marco sociopolítico, son muy escasas las demandas de los trabajadores del campo que se siguen por los cauces legales establecidos, lo normal suele ser el recurso a prácticas no regladas e ilícitas, independientemente que para el trabajador sean vistas como medidas "legítimas" para alcanzar su "justicia". Igualmente, los distintos tipos de manifestaciones presentan, salvo casos muy concretos, una ínfima o nula organización, lo cual, por un lado, limita el

${ }^{61}$ Sobre esta normativa y su aplicación en la provincia de Cádiz, GONZÁLEZ BELTRÁN, J.: Reformismo y administración local en la provincia de Cádiz durante el reinado de Carlos III, Jerez de la Frontera, 1991, pp. 406-490.

62 Entre 1745 y 1805 la documentación consultada en los archivos municipales de Jerez de la Frontera y El Puerto de Santa María nos ofrecen 39 conflictos, a los que añadimos otros 7 aportados por la bibliografía utilizada. En total 46 casos. 
éxito de las mismas, pero, por otro, las hace más inquietantes, por ser imprevisibles, y se dificulta su posible persecución y represión.

Las reclamaciones pacíficas y legales son las que utilizan para expresarse la negociación y el recurso a la justicia. Negociar, cuando las diferencias sociales, económicas y culturales son tan notables, resulta verdaderamente difícil, más cuando una de las partes, los empleadores, suele contar con el apoyo de las autoridades y de los jueces. Del mismo modo, las normas laborales no van en el sentido de favorecer la negociación, sino más bien en el de imponer determinadas condiciones. Finalmente, se limita la capacidad de concertación al predominar el acuerdo oral individual, por el cual el empleador contrata uno a uno a aquellos jornaleros que aceptan su oferta de trabajo y las condiciones del mismo. A lo sumo, la contratación se realiza mediante un manijero o peón de mano que representa a una cuadrilla de trabajadores. No obstante, los operarios del campo solían aprovechar determinadas circunstancias, tales como la escasez de empleados o la obligación de realizar alguna faena con rapidez, para obtener alguna mejora en las condiciones laborales ${ }^{63}$.

Pero si complicada es la negociación mucho más complejo resulta el recurso a la vía judicial. En primer lugar, porque los jueces se sitúan, casi siempre, al lado de los empleadores, algo que por otra parte no es difícil, puesto que tan sólo basta con aplicar la restrictiva reglamentación laboral, auspiciada por éstos, contraria a los intereses de los trabajadores. Y segundo, por que la justicia se caracteriza por ser lenta y costosa. Dos ejemplos nos ilustran sobre estos aspectos. En 1784 D. Diego Caballero, en representación de "todos los pobres de Algeciras", reclamaba el reparto en suertes de una dehesa municipal entre los braceros de la localidad, llegando al año 1800 sin que se dictara una resolución definitiva sobre la propuesta. Mucho tiempo son 16 años si, además, no se consigue nada. Por otro lado, en 1778, los braceros unidos a los pequeños labradores de Jimena de la Frontera, declaraban haber gastado 4.500 reales en el pleito para obtener el reparto de tierras, a pesar de lo cual no habían conseguido nada "por ser la parte contraria rica y poderosa y en el día de hoy no hay más razón que el dinero" ${ }^{64}$. Como podemos apreciar el recurso a los tribunales superiores o directamente al rey a través del Consejo de Castilla se utiliza, casi exclusivamente, para los problemas de repartos de tierra en aplicación de las leyes de 1767 y 1770, cuando lo que está en juego es la oportunidad de obtener algo tangible: un trozo de tierra que puede asegurar el sustento familiar. No obstante, falta por realizar un estudio de las fuentes judiciales, Chancillería de Granada y Audiencia de Sevilla, que quizás nos mostraran un recurso a la justicia por problemas laborales más copioso del que hasta ahora tan sólo suponemos.

Agotadas o no utilizadas, por su dificultad, estas vías legales, se le abren al trabajador del campo, al margen del orden establecido, una amplia tipología de manifestaciones de protesta o queja, las cuales, en general, varían dependiendo del problema concreto de que se trate.

Así, la demanda no atendida de tierras para cultivar, antes de promulgarse las leyes de repartos, originaba la usurpación de pequeñas superficies de terrenos en comunales, bal-

63 RUSSO, S.: Art. Cit., p. 73, señala el fuerte poder contractual de los jornaleros italianos al utilizar a su favor la "inopia operatorium" y el "excessivum calorem" que no permitía retrasar la siega.

64 Estos ejemplos en A.H.N., Consejos, leg. 2.011, exp. 44 y leg. 992, exp. 29. Sobre los problemas de recurrir a la justicia ORTEGA, M.: Conflicto y continuidad en la sociedad rural española del siglo XVIII, Madrid, 1993 , pp. 75-94. 
díos y caminos. En Jerez de la Frontera, se detectan entre los años 1750 y 1770 varios expedientes contra individuos que, con el pretexto de poner colmenas, habían establecido pequeñas explotaciones agrícolas, en torno a 2 hectáreas de media. En 1755, por ejemplo, se denunciaba a 45 personas que, entre todas, tenían sembradas 87,8 hectáreas ${ }^{65}$. A raíz de la promulgación de la normativa de repartos, las reclamaciones, al tener una base legal, se hacen normalmente, tal como hemos visto, a través de los cauces judiciales ${ }^{66}$.

En materia de condiciones laborales las muestras de protesta o reclamación, al margen de la legalidad, conllevaban serios inconvenientes, pues la maquinaria punitiva solía actuar efectivamente. Por ello, salvo escasas ocasiones, la manifestación de protesta se reduce a formas de resistencia pasiva y de obstrucción: entorpecer la contratación, incumplimiento de los contratos con abandono del trabajo, alargar el tiempo de los desplazamientos, reducir la productividad trabajando más despacio, etc.. En la documentación consultada en el archivo de Jerez de la Frontera descubrimos varios ejemplos. Así, en 1769, se informa por los cosecheros al cabildo que "resentidos los trabajadores del campo del bando publicado", por el se concretaba la jornada laboral, habían puesto en práctica una "nueva corruptela”, que consistía en "querer venir de las viñas entrando el mes de abril hasta concluir el verano luego que comen, como si en este tiempo no se les pagase el jornal como el invierno”. En 1782, se denuncia la presencia en la localidad de determinadas personas "con el malicioso intento de entibiar a los otros que quieren ir a cumplir sus contratas”. Y, en 1784, se señalaba como los trabajadores "con el asilo de aguardar quien les ofrezca más se quedan rezagados en las esquinas o sitios a donde lo buscan y ajusta cada capataz por lo que quiere" ${ }^{\text {" }}$.

El enfrentamiento directo aflora muy pocas veces, pero se da. Detectamos el recurso a lo que hoy denominamos huelga, una práctica que, aunque esporádica, por su mayor incidencia suele quedar registrada en la documentación y de la que se tienen noticias incluso desde el siglo XVI ${ }^{68}$. En 1799, los labradores de Jerez temían por la pérdida de la cosecha, siendo el motivo,

"el abandono a que voluntaria y maliciosamente se entregan los operarios de campo, ya faltando al cumplimiento de los contratos que celebran, ya reduciéndose a NO QUERER SALIR A TRABAJAR POR EL ANTOJO Y CAPRICHO de querer ganar jornales que en años abundantes y de escasez de gentes no se han experimentado, de que dimana que todas las faenas estén paradas ${ }^{\prime 6}$.

A.M.J.F., leg. 142, exp. 4387.

66 Los repartos de tierra crearon un sentimiento colectivo en los sectores de jornaleros y pequeños campesinos, que dan lugar a métodos más organizados. Así, se llegan a utilizar cofradías religiosas como tapadera de las reuniones y para obtener fondos. WINDLER-DIRISIO, Christian: "Campesinos pobres y absolutismo reformista”, Noticiario de Historia Agraria, 7 (1994), pp. 67-107. O se forman "partidos” para ganar las elecciones de diputados y personeros y, de esta forma, tener voz en los cabildos municipales. SÁNCHEZ LORA, J.L.: Op. Cit., p. 85.

67 A.M.J.F.,leg. 171, exps. 5.307 y 5.310 y A.C., cabildo 30-8-1784, f. 460.

68 CORTES PEÑA, A.L.: Op. Cit., p. 52, señala como los trabajadores de Iznatorafe, en 1565, se negaban a recoger la cosecha si no se les aumentaba el salario. Lo mismo ocurrió en Córdoba en 1595, según recoge VASSBERG, D.E.: Tierra y sociedad en Castilla, Barcelona, 1986, pp. 251-252. También en Morón en 1682, donde los trabajadores "se confederaban unos con otros para no bajar cosa alguna de la cantidad que piden", SÁNCHEZ LORA, J.L.: Op. Cit., p. 78.

69 A.M.J.F., Histórico reservado, cajón 6, no 30, ff. 811-815. En 1795, en Velez-Rubio tuvo lugar un incidente similar. DOMÍNGUEZ ORTIZ, A.: Sociedad y Estado en el siglo XVIII español, Barcelona, 1976, p. 417. 
Y en esa misma conflictiva década de final de siglo, en concreto el 16 de abril de 1792, tuvo lugar en Jerez un motín de los trabajadores de las viñas, siendo el motivo haberse dictado un bando regulando la jornada de trabajo, por el que se exigía salir más temprano para las explotaciones. Los trabajadores, en torno a 4.000, se dirigieron a la plaza mayor en la que se encontraba la morada del corregidor, al cual reclamaron que "se guardase la antigua costumbre y se publicara del mismo modo", lo cual concedió el dicho corregidor tras salir al balcón, con lo que se apaciguaron los ánimos y cesó el tumulto. Las autoridades locales, al informar al Consejo de Castilla, restaban importancia a lo sucedido, quizás para encubrir su propia culpa, y decían que no se había,

\begin{abstract}
"usado de voz violenta, ni acción, sino de suplicatorias, con la imprudente rústica expresión de que fuese en aquel día, cuyo caso, aunque persuadida la ciudad a que no hubo espíritu de inobediencia, sino sólo de suplicación de gente inculta"70.
\end{abstract}

El problema del paro estacional presenta unas manifestaciones de protesta peculiares. La primera de ellas es muy tradicional e, incluso, permitida y fomentada por la propia sociedad, se trata de la solicitud de limosna. La moral cristiana exhortaba a la práctica de la caridad, que era ejercida por las instituciones, civiles y, preferentemente, eclesiásticas, y también por los particulares. Pero lo que no se admitía era el que la solicitud se convirtiera en una imposición, y en ello se convertía la petición de ayuda cuando se realizaba a través de cuadrillas de trabajadores desempleados que recorrían las calles y los campos, aplicando en ocasiones la coacción. No sólo pedían pan y dinero, sino que llegan a exigir que se les proporcione trabajo. En jerez, un capataz alegaba, en 1782, que aunque no necesitaba contratar a nadie, "hasta 17 hombre, llevados de su necesidad, por no tener otro trabajo, se presentaron en la viña el lunes y por remediar su necesidad los ocupó en binar y coger cigarras y agostar", y mucho más violenta tuvo que ser la escena que se desarrolló en 1793, según la relata el capitular D. Vicente Ferrer. Cuando éste, comisionado por la ciudad para las obras públicas que se habían acordado emprender para dar trabajo a los desempleados, se disponía a ocupar a 200 individuos, aparecieron muchos más, y al intentar convencerlos para que buscaran otro destino, "reunidos todos los operarios dijeron que se irían en hora buena pero que les diesen pan, y al ver esta confusión se determinó que siguiese el trabajo"71 , quedando empleados hasta 1.500 hombres. No debía de resultar sencillo negarse a la "petición" de una muchedumbre de personas apretadas por la penuria.

De la impetración con coacción al hurto o robo existía un escaso margen. Por ello, en los periodos de desempleo amplio, y con carestía de alimentos incluida, el recurso a obtener por la fuerza las subsistencias se multiplica. En Jerez de la Frontera hay alusiones a estas prácticas delictivas en 1763, 1778, 1780, 1785, 1786, 1792 y 1793. De este último año resulta esclarecedora la exposición efectuada por el síndico personero en una reunión del

70 Tenemos dos versiones del motín. Una en A.M.J.F., A.C., cabildo 18-4-1792, ff. 133-134. Y otra en TRILLO Y BORBÓN, Juan de: Libro en donde están apuntadas todas las novedades acaecidas en esta ciudad de Jerez de la Frontera desde el año 1753, y algunas otras que han transcurrido fuera de ella, Jerez, 1890, p. 35.

71 A.M.J.F., leg. 171, exp. 5.309 y leg. 331, exp. 9.799. 
cabildo en la que se discutía sobre la necesidad de continuar el socorro a "los pobres jornaleros". El cargo electo plateaba las siguientes interrogantes:

“¿admite duda que para socorrer el pueblo de pan le es preciso a los panaderos para conducir las cargas de él a la panadería valerse de tropas para custodiarlas?. ¿admite duda que no se puede salir del pueblo con ningún pan, ni otros comestibles para el socorro de los ganaderos porque abanderizados ya los trabajadores en grandes cuadrillas acometen a los que los conducen y no contentos con llevarse el pan y demás los maltratan?. ¿admite duda que al golpe de la oración no se puede salir de las casas por no sufrir los repetidos insultos hechos a los vecinos y particularmente a muchos capitulares?"72.

Lo que no admite duda es que en la última década del siglo XVIII, en plena crisis finisecular con un diáfano enfriamiento de la economía, la situación social de los muy numerosos asalariados agrícolas se había deteriorado enormemente, favoreciendo la intensidad de los conflictos y el extremismo de las acciones de protesta.

Llegados a este punto conviene plantearse unas interrogantes. ¿Cuál fue la efectividad de estas reclamaciones de los trabajadores?. ¿Cómo repercutieron sobre las condiciones laborales y sobre las condiciones de vida de los propios operarios?. ¿Qué respuesta obtuvieron de las autoridades?.

Comencemos contestando a esta última cuestión. El profesor José Andrés Gallego indica que la respuesta habitual de los gobernantes solía ser doble, por una parte, se reprimía la protesta, generalmente de forma leve, aunque hay excepciones de dureza, y, por otra, se aceptaban las reivindicaciones en todo o en parte ${ }^{73}$, eso sí, muchas veces de forma temporal mientras que la situación era reconducida a la normalidad.

La represión responde tanto a la pretensión de restablecer el orden social alterado como al temor de los grupos dirigentes al posible "furor" de unos trabajadores descontentos, rudos e incultos. Las medidas represivas presentan una amplia gama dependiendo del tipo de acción delictiva que se quiere reprimir y de la virulencia que lleguen a alcanzar. Se empieza por restringir determinados actos de los trabajadores, tales como juntarse en el lugar donde se estuvieran fijando los salarios, para evitar cualquier tipo de intimadación, o el formar cuadrillas para la petición de limosna, tal como ordenaba el corregidor de Jerez en 1763: "que ningún trabajador forme cuadrilla que pase de DOS para pedir limosna y esto sea de día y con el modo correspondiente sin cometer fuerza ni violencia alguna" 74 . Estas y otras prohibiciones iban siempre acompañadas de amenazas de multas, las cuales solían ser poco efectivas, ya que los jornaleros casi nunca tenían dinero para pagarlas, por lo que los alguaciles, que percibían una parte de lo recaudado por la sanción, no ponían mucho empeño en ir contra los trabajadores infractores. Por ello, cada vez más, se pone el acento en decretar penas de prisión y en aplicar los castigos recogidos en las leyes contra vagos y maleantes. De esta forma, las reivindicaciones laborales de los trabajadores del campo son tratadas como actos de delincuencia que caen en la esfera de la justicia penal, lo que da un nuevo elemento de control a los empleadores. En último caso, y si la situa-

A.M.J.F., A.C., cabildo 16-4-1793, ff. 92-96.

ANDRÉS GALLEGO, J.: Op. Cit., p. 33.

${ }^{4}$ A.M.J.F., Histórico reservado, cajón 6, nº 30, f. 284. 
ción así lo aconsejaba, estaba el recurso al ejército como medida coercitiva para aplacar los ánimos. En jerez, el cabildo solicitó al Capitán General de la zona, el envío de tropa los años 1780 y 1785 .

Pero, hemos dicho que las autoridades no sólo reprimen, sino que, también, suelen acceder, no tanto por justicia sino más bien por temor, a todas o parte de las reclamaciones efectuadas por los trabajadores, que de esta forma comprueban la efectividad de unas medidas de presión, que empiezan a formar parte de su cultura del trabajo.

En los periodos de desempleo y carestía logran que a las limosnas tradicionales de las instituciones eclesiásticas y de los particulares se una, de forma regular, el reparto de pan por parte del gobierno municipal. Los concejos, salvo situaciones de crisis de subsistencias, eran muy reacios a utilizar el trigo de los graneros municipales, los pósitos, que tenían como función primordial prestarlo a los labradores que lo necesitasen para la siembra. Parece, y así lo hemos comprobado, que, desde la década de 1780, el paro invernal de los trabajadores del campo se considera, por la presión ejercida por éstos, situación crítica, no de hambre, sino de orden público.

El problema descrito debía de afectar a muchas localidades, puesto que las autoridades superiores empezaron a tomar cartas en un asunto que, de esta manera, se convertía en cuestión de Estado. Por un lado, no dejaban de reconocer el peligro que suponían unos trabajadores sin empleo y hambrientos, sobre todo cuando las noticias que llegaban de Francia eran de revolución y de desmanes de las clases populares. Pero, por otro, conocían el alto coste financiero que tenían las limosnas de pan para las arcas municipales. Teniendo en cuenta estos dos aspectos, e imbuidas de un nuevo espíritu utilitario, empezaron a enviar órdenes a los municipios aconsejando que la limosna no fuera "gratuita", es decir, se exigiera al que la recibía una contraprestación que consistiría en realizar determinados trabajos en obras públicas o de interés común. Así, en 1785, el Capitán General Conde $\mathrm{O}^{\prime}$ Reilly indicaba al consistorio jerezano que,

"el verdadero alivio de los pobres jornaleros es el proporcionarles
trabajo, de esto resulta su beneficio, el disipar los vagos y
malentretenidos que no hallarían pretextos para sus extorsiones y el evi-
tar que los mismos buenos jornaleros no tomen apego a la ociosidad y
prefieran el continuar de pordioseros a restituirse a sus labores".

Para, a continuación, ofrecer trabajo en las obras de caminos que, bajo su dirección, se desarrollaban en la zona. Igualmente, en octubre de 1803, el Consejo de Castilla ordenaba, de manera general, a las autoridades locales que estudiaran que obras públicas eran necesarias para en ellas "dar ocupación a los necesitados el tiempo que haya de durar la indigencia", ya que el año se presentaba estéril y habría pocas labores que realizar en los campos. El Consejo argumentaba la orden comentado que estaba convencido de...

"la necesidad de tomar providencias eficaces y activas para el mantenimiento del pobre jornalero en la temporada rigurosa del invierno, y prevenir el crimen, el hambre, las enfermedades y demás resultas perniciosas que de ella se originan" 75 .

75 Carta del Capitán General a Jerez el 10-1-1785, A.M.J.F., A.C., cabildo 13-1-1785, f. 47. Orden del Consejo de Castilla, Madrid 7-10-1803, en A.M.P.S.M., leg. 1.651. 
Incluso, no faltaron iniciativas, generalmente abocadas al fracaso por la carencia de recursos financieros que permitieran llevarlas a cabo, para fundar montepíos con la finalidad de prestar ayuda económica a los trabajadores durante las paradas en las labores del campo $^{76}$.

En el aspecto estrictamente laboral, además de tener en contra a las autoridades, los operarios debían de llegar a convenios con unos empleadores que defendían intereses totalmente contrapuestos a los suyos. Pero las diversas formas descritas de manifestar los trabajadores sus demandas y reclamaciones parecen que, también en este campo, tuvieron su fruto.

No es nada fácil seguir la evolución de los salarios en el siglo XVIII, ya que faltan estadísticas oficiales y las contabilidades particulares son, además de difícil localización, bastante escasas. Por otra parte, estarían las diferencias salariales en función de los distintos trabajos a realizar, el carácter fijo o temporal del operario, etc.; sin olvidar la disparidad dependiendo de cada comarca o localidad. En general, en la Andalucía del siglo XVIII, en cuanto a los salarios, se distinguen dos periodos muy opuestos: la primera mitad, entre 1715 y 1770, que presenta unos salarios bajos y estancados; y la segunda mitad, 1770-1818, en la que los jornales muestran una clara tendencia alcista ${ }^{77}$.

El profesor Pierre Ponsot, utilizando datos de contabilidades de explotaciones agrícolas, nos ofrece las series de salarios, para determinadas tareas, que se abonaban en la ciudad de Jerez durante el siglo XVIII ${ }^{78}$. A través de estos datos podemos comprobar la evolución mencionada con un incremento constante de los salarios que se abonaban por las distintas tareas agrícolas. Si en el quinquenio de 1751-55 un trabajador de la vid ganaba, de media, 4,1 reales al día, en los años 1786-90 percibía hasta 7,3 reales. Los empleados en los cortijos pasan de los 3,6 reales, de media, en el quinquenio 1751-55 a ganar 7,2 reales diarios en los años 1786-90. No cabe duda que la modificación del marco legal, en 1767, al dejar sin vigencia las tasas y límites en los salarios que, normalmente, establecían las autoridades locales, permite hacer más efectivas las reclamaciones de los trabajadores y forzar una concertación con mayores márgenes de libertad y más en consonancia con la situación real del mercado de trabajo.

Otra cuestión aparte es si esta subida significó un aumento del poder adquisitivo de los trabajadores agrarios, en una época de alza constante de los alimentos y de otros productos. La mayoría de los autores recalcan que el incremento de los jornales sigue una línea paralela a la de los precios del trigo o del pan, pero siempre por debajo de éstos, por lo que los jornaleros no perciben una mejora significativa de su nivel de vida ${ }^{79}$. En Jerez, por

$76 \quad$ A los problemas financieros para su creación hay que añadir los obstáculos burocráticos. La propuesta de establecer un montepío y hospicio en Jerez se debatió en el Consejo de Castilla, sin resultado alguno, entre 1785 y 1791. A.H.N., Consejos, leg. 1.453, exp. 38 .

77 Así lo corroboran los estudios de HALMITON, Earl J.: Guerra y precios en España 1651-1800, Madrid, 1988, p. 249 y ANES, Gonzalo: Las crisis agrarias en la España Moderna, Madrid, 1970, pp. 427-438, que marcan el límite de la subida salarial en torno a 1790-1795. Por su parte, GUTIÉRREZ BRINGAS, M.A.: "El intento de reconstruir una variante del nivel de vida del campesinado: los salarios agrícolas en España, 1756-1935", en VIII Congreso de Historia Agraria, Salamanca, 1997, preactas, pp. 73-90, señala como en la provincia de Cádiz el aumento salarial continuó hasta, al menos, 1818.

78 PONSOT, P.: Atlas de historia económica de la Baja Andalucía (siglos XVI-XIX), Granada, 1986, pp. 549-557. Hay que tener en cuenta que los salarios que se pagaban en Jerez y localidades cercanas eran de los más altos que se abonaban en Andalucía.

79 Corroboran esta idea de pérdida de poder adquisitivo, a pesar de la subida de salario, los trabajos de FLORENCIO PUNTAS, A. y LÓPEZ MARTÍNEZ, A.L.: "El mercado de trabajo...", p. 82 y ROCA FABREGAT, P.: Art. Cit., p. 85 . 
ejemplo, los jornales, en su conjunto, se revalorizan, se incrementan, porcentualmente, por encima de los granos y, más en concreto, del trigo. Pero si en vez de los porcentajes de aumento nos fijamos en los precios y salarios nominales la mejora de los trabajadores no es tan clara e, incluso, se puede apreciar una perdida del poder adquisitivo. Con la información que contamos podemos calcular que en la década de 1751-60 un trabajador agrícola necesitaba 6,65 jornales para adquirir una fanega de trigo, mientras que en los años 80 del siglo, a pesar de la fuerte y continuada subida de los salarios desde 1771, el operario del campo precisaba 7,15 jornales para conseguir una fanega de trigo.

Igualmente, los operarios del campo, a fuerza de oponerse a determinadas condiciones laborales, forzaron la elaboración de nuevas reglamentaciones en las que sus quejas y peticiones iban siendo incorporadas, por lo que nos encontramos con ordenaciones en las que los trabajadores, además de obligaciones, empiezan a tener derechos. Por ejemplo, en 1790, una junta de labradores jerezanos, junto con el corregidor, sin presencia de los trabajadores, redactó unas reglas en las que se recogían los siguientes aspectos beneficiosos para los asalariados: a) los empleados a destajo deberían ver, previo al acuerdo económico con el empleador, los sembrados para evitar cualquier caso de engaño; b) a los operarios, en el momento de contratarlos, se les ofrecería un salario concreto; c) en el caso de no haberse llevado a cabo la obligación anterior, el trabajador cobraría el sueldo medio que se estuviera pagando en la zona; d) los empleadores no podrían despedir a los cuidadores del ganado "sin justa causa"; y e) el labrador que hubiera "ofrecido al jornalero la temporada de costumbre y no tenga trabajo para completársela haya de cumplir precisamente lo que ofreció" ${ }^{80}$.

Todo lo expuesto, nos descubre como los trabajadores del campo andaluces en la segunda mitad del siglo XVIII estaban logrando una mejora de sus condiciones laborales y una mayor atención a sus problemas por parte de las autoridades, utilizando para este fin la reiteración de una serie de prácticas de protesta y reclamación que, salvo algunas excepciones en las que el conflicto aflora abiertamente, se caracterizan por su mínima organización, por la carencia de objetivos globales (no se pretende modificar el marco sociopolítico) y por la moderación de sus acciones, a pesar de lo cual se muestran bastante efectivas.

${ }_{80}$ A.M.J.F., Histórico reservado, cajón 6, no 30, ff. 722-728. 